\title{
MANAGEMENT OF ENDOCRINE DISEASE Optimal feminizing hormone treatment in transgender people
}

\author{
Dorte Glintborg®1, Guy T'Sjoen², Pernille Ravn³ and Marianne Skovsager Andersen' \\ ${ }^{1}$ Department of Endocrinology, Odense University Hospital, Odense, Denmark, ${ }^{2}$ Department of Endocrinology and \\ Center for Sexology and Gender, Ghent University Hospital, Ghent, Belgium, and ${ }^{3}$ Department of Gynaecology and \\ Obstetrics, Odense University Hospital, Odense, Denmark
}

Correspondence

should be addressed to D Glintborg

Email

dorte.glintborg@rsyd.dk

\begin{abstract}
Transgender women are assigned male at birth but identified as women. The incidence of gender dysphoria is estimated to be around $1 \%$ of the population. Gender dysphoria may be associated with depression and low quality of life, which in most cases improves during gender-affirming hormonal treatment (GAHT). Feminizing hormonal treatment for transgender women or gender non-binary people typically includes natural estrogen (estradiol). Additional testosterone-blocking treatment is often needed to ensure the suppression of the pituitary-gonadal axis and may include cyproterone acetate, a gonadotropin-releasing hormone agonist ( $\mathrm{GnRH}-\mathrm{a})$, or spironolactone. The health risks of cyproterone acetate as anti-androgen treatment are debated and randomized protocols with other antiandrogen treatments are requested. Orchiectomy is performed in some transgender women after various duration of GAHT. Currently, natural progesterone is not recommended as part of GAHT due to limited knowledge on the balance between risks and benefits. In the present article, we discuss evidence regarding established and upcoming feminizing treatment for adult transgender women or gender non-binary people seeking feminization. Data on study populations with transgender women are put into a wider context of literature regarding the effects of sex steroid hormones in cisgender study populations. Relevant follow-up and monitoring during feminizing treatment is debated. The review has a special focus on the pharmacotherapy of feminizing hormonal therapy.
\end{abstract}

\section{Invited Author's profile}

Dr Dorte Glintborg currently working as a consultant and associate professor at Odense University Hospital, Department of Endocrinology. Her areas of clinical work involve the pituitary, adrenal and gonadal diseases, PCOS, transgender care, and bariatric surgery. She is a responsible senior consultant at CGI-Odense (Center for transgender care). Scientific focus areas include hirsutism and PCOS, pituitary and adrenal diseases, hypogonadism, transgender care, Odense Child Cohort, and Body Identity Clinic, Odense. She is an important member of the Nordic PCOS awareness Group and the European network for the investigation of gender incongruence: The ENIGI initiative.

(C) 2021 European Society of Endocrinology Printed in Great Britain
Published by Bioscientifica Ltd 


\section{Introduction}

The term transgender is used to describe individuals, whose gender identity differs from the assigned gender at birth. Transgender women are persons assigned male at birth but identified as women. In a recent European study, $0.7-1.1 \%$ of the general population reported incongruent gender identity (1).

In transgender persons, about one out of three identifies as gender non-binary (2). Gender non-binary is an umbrella term for gender identities that are neither male nor female - identities that are outside the gender binary (2). Gender non-binary people may also seek feminization. Medical doctors are needed to prescribe hormone therapy in most of Europe, the United States, and Canada, but gender-affirming hormonal therapy (GAHT) may also be obtained from unofficial sources. In many countries, GAHT is predominantly prescribed by centers with a special interest in transgender health, also called gender teams. These multidisciplinary gender teams initiate and offer psychological support before and during the transition and prescribe GAHT. Furthermore, the gender teams help to coordinate referrals for genderaffirming surgery and the involvement of other specialists (dermatology, plastic surgery, urology, gynecology, otorhinolaryngology, etc.). Current guidelines and position statements describe the initial assessment of transgender women $(3,4)$.

GAHT in transgender women aims for the development and maintenance of secondary feminine characteristics and suppression of secondary masculine characteristics. Feminizing hormonal treatment usually includes natural estrogen (estradiol, E2) alone or in combination with testosterone-blocking treatment (1). E2 is administered transdermally, orally, or as injections (5). Anti-androgen treatment may include cyproterone acetate (CPA), a gonadotropin-releasing hormone agonist (GnRH-a) or spironolactone (5). Anti-androgen treatment is discontinued if the patient undergoes orchiectomy or if estrogen-only treatment has proven sufficient.

In the present review, we discuss evidence regarding established and upcoming methods for feminizing treatment in adult transgender women and gender nonbinary women with a wish for feminization. We put available data on GAHT into a wider context of literature regarding the effects of sex hormones in cisgender study populations. The review has a special focus on the pharmacotherapy of feminizing hormonal therapy.

\section{Methods}

The paper was designed as a narrative review regarding GAHT in adult transgender women. We searched for available clinical trials and placebo-controlled trials in study cohorts of adult transgender women published until December 2020 in PubMed. We performed a search using the term 'transgender' in combination with one of the terms: placebo-controlled trial, clinical trial, medicine prescription, drug prescription, gender-affirming hormonal therapy. The search term 'transgender' was replaced with trans-sexualism, gender incongruence, trans female, and trans woman. We also searched for papers including each identified treatment modality: estrogen, estradiol, spironolactone, antiandrogen, androgen blocker, androgen antagonist, cyproterone acetate, cyproterone, flutamide, finasteride, gonadorelin, GnRH-a, progestogen, progesterone, progestin, thus including all hormonal feminizing treatments, in combination with one of the search terms for transgender. Further relevant studies were identified by cross-search from reference lists in identified studies. We excluded studies regarding the treatment of children/ teenagers $<18$ years (puberty blockers) and studies focusing on surgical procedures. Dermatologic treatment of hirsutism is covered in other recent reviews $(6,7)$ and is not covered in this paper. Lifestyle intervention, treatment of weight problems, and gender-affirming surgical interventions are considered outside the scope of this paper. Datasets on hormone treatment in gender non-binary people are lacking and, therefore, this is not specifically addressed, although we acknowledge that some papers in this review may include gender nonbinary persons seeking feminizing treatment. In case of limited literature in transgender study populations, we included and discussed studies performed in cisgender study populations. Furthermore, knowledge regarding the effects of sex hormones in cisgender study populations was discussed in the context of transgender health.

\section{Gender-affirming hormonal treatment (GAHT)}

In transgender women, the desired effect of GAHT is the development of secondary female characteristics including breast growth and female body composition. Anti-androgen treatment may be needed to ensure the full 
suppression of the pituitary-gonadal axis and suppression of secondary male characteristics such as terminal body hair growth.

\section{Estrogen treatment}

Background

The most important endogenous estrogens include $17 \beta$-estradiol (E2), estrone (E1) and estriol (E3), where E2 is found at the highest concentration and is the most potent estrogen. E2 acts on the nuclear estrogen receptors $\alpha$ and $\beta$, which leads to different transcriptional effects. Apart from genomic effects, E2 can activate nongenomic G-coupled estrogen receptors (8). The E2 level in adult cisgender men is around $0.1 \mathrm{nmol} / \mathrm{L}$ compared to $0.4-0.5 \mathrm{nmol} / \mathrm{L}$ in premenopausal women at mid-cycle (9). In cisgender men, 75\% E2 is produced by peripheral aromatization of testosterone (9). The biological roles of E2 in males include endothelial repair and regeneration, decrease of body fat, preservation of bone health, and increase of growth hormone secretion $(9,10)$.

Estrogen can be given synthetically as ethinyloestradiol (oral contraceptives) or naturally as E2. Pro-coagulant side effects of synthetic estrogens are well described (11), which makes treatment with ethinylestradiol obsolete for GAHT. E2 is considered as first-line drug for GAHT in transgender women. E2 can be applied orally, trans-dermally, or as i.m. injections. Table 1 gives an overview of the different treatment regimens of E2. Oral E2 is metabolized in the intestines and liver into E1 and estrogen conjugates before entering the circulation (first-pass metabolism) (12). As a result, the ratio of circulating E1/E2 is 5/1 after oral E2 compared to $1 / 1$ after transdermal E2. Transdermal E2 gives a more constant, non-fluctuating serum E2 without circulating estrogen metabolites, which may be advantageous in terms of cardio-metabolic side effects (13). According to current treatment guidelines, transdermal E2 is considered as first-line treatment in transgender women $>40$ years $(14,15,16)$. Intramuscular E2 is associated with a peak in E2 (Table 2) lasting for about 2 weeks and reaching values up to six times higher than the average E2 concentration in cisgender women (17). Such high serum E2 levels may potentially be associated with thromboembolic events. In most European countries, i.m. injections are not available. Buccal E2 can be used for the treatment of hot flashes in postmenopausal women (18); however, the use of buccal E2 in transgender women may be limited by lower concentrations and fluctuating E2 levels (19). Studies regarding feminizing effects of GAHT most often evaluated breast growth, whereas other outcomes are less evaluated. Studies comparing efficacy depending on

Table 1 GAHT, recommended treatment modalities in transgender women. GAHT modalities not currently recommended are not included in the table (5-alfa reductase inhibitors, flutamide, progesterone etc). Information adapted from $(3,92,109)$.

\begin{tabular}{|c|c|c|c|c|}
\hline Content/form & Content & Dosage & Time to peak & Pharmacokinetics \\
\hline \multicolumn{5}{|l|}{ E2 } \\
\hline Patch & $\begin{array}{l}\text { E2 in polymeric acrylate } \\
\text { or vinylacetate }\end{array}$ & $\begin{array}{l}\text { One patch every } 3 \text { days } \\
0.05-0.15 \mathrm{mg} \mathrm{E} 2 / 24 \mathrm{~h}\end{array}$ & $8-12 \mathrm{~h}$ & $\begin{array}{l}\text { E1/E2 ratio: } 1 \text {; Constant delivery of E2 } \\
\text { for } 7 \text { days; No accumulation of E2; } \\
\text { Half-life: } 24 \text { h }\end{array}$ \\
\hline Gel/spray & E2 in alcoholic gel & Gel daily $0.8-3 \mathrm{mg} /$ day & $4-6 h$ & $\begin{array}{l}\text { E1/E2 ratio: } 1 \text {; No accumulation of E2; } \\
\text { Steady state within } 3 \text { days; Half-life: } \\
36 \mathrm{~h}\end{array}$ \\
\hline Tablet & E2 & 2-6 mg/day & $2-4 \mathrm{~h}$ & $\begin{array}{l}\text { High E1/E2 ratio (due to first-pass } \\
\text { metabolism in gut and liver); } \\
\text { Gradual accumulation of E2 in } \\
\text { blood; Steady state reached within } \\
\text { days; Half-life: } 12 \mathrm{~h}\end{array}$ \\
\hline $\begin{array}{l}\text { Intramuscular } \\
\text { injection }\end{array}$ & E2 in oily solution & $\begin{array}{l}\text { 2-10 mg/injection every } \\
1-2 \text { weeks (depending } \\
\text { on solution) }\end{array}$ & $\begin{array}{l}\text { 2-4 days } \\
\text { (depending on } \\
\text { solution) }\end{array}$ & E1/E2 ratio: 0.5; Half-life: $1-2$ weeks \\
\hline \multicolumn{5}{|l|}{$\begin{array}{l}\text { Cyproterone } \\
\text { acetate }\end{array}$} \\
\hline $\begin{array}{l}\text { Tablet } \\
\text { Spironolactone }\end{array}$ & Cyproterone acetate & $\leq 10 \mathrm{mg} /$ day & $2-3 h$ & Metabolized in liver; Half-life: 48-72 h \\
\hline Tablet & Spironolactone & $100-400$ mg/day & $1-4 h$ & Metabolized in liver; Half-life: 16-22 h \\
\hline $\begin{array}{l}\text { GnRH-a } \\
\text { Subcutaneous or } \\
\text { i.m. injection }\end{array}$ & Leuprolide/triptoreline & $3.75-45 \mathrm{mg} / 1-6$ months & $1-4 \mathrm{~h}$ & Metabolized in liver; Half-life: 3 h \\
\hline
\end{tabular}


Table 2 GAHT, directions for choice of treatment.

\begin{tabular}{|c|c|c|c|c|}
\hline & First choice & $\begin{array}{l}\text { Second } \\
\text { choice }\end{array}$ & Not recommended & Debated \\
\hline Estrogen & $\begin{array}{l}\text { E2: Dermal; Oral } \\
\quad(<40 \text { years old })\end{array}$ & E2: Oral & Oral contraceptives & Buccal E2 \\
\hline Anti-androgen & $\begin{array}{l}\text { Spironolactone; } \\
\text { CPA; GnRH-a }\end{array}$ & & $\begin{array}{l}\text { 5-alfa reductase } \\
\text { inhibitors; Flutamide }\end{array}$ & $\begin{array}{l}\text { CPA vs spironolactone vs GnRH-a; Timing of } \\
\text { orchiectomy; Reduction of CPA dosage }\end{array}$ \\
\hline Adjunctive treatment & & & & Progesterone: Natural vs progestins \\
\hline
\end{tabular}

CPA, cyproterone acetate; E2, estradiol.

the route of E2 application in transgender women are sparse (20) and are discussed further below. Most studies applied combined treatment regimens, which makes the individual effects of different estrogen preparations and antiandrogen drugs difficult to evaluate.

\section{Anti-androgen treatment}

The mostcommonlyused antiandrogen treatmentsareCPA, GnRH-a, and spironolactone. Anti-androgen treatment is, for many, a cornerstone of feminizing treatment. E2 treatment in transgender women ensures serum E2 within reference interval for cisgender women, but the pituitarygonadal axis will often not be sufficiently suppressed by E2 treatment alone. Testosterone is an important masculinizing and anabolic hormone. The masculinizing effects of testosterone include the stimulation of the male reproductive tract and development of secondary sex characteristics (e.g. terminal hair growth), whereas the anabolic effects of testosterone include the stimulation of somatic tissue, such as muscle. Testosterone acts as a prohormone and is converted to the biologically active derivate dihydrotestosterone (DHT) by the enzyme $5 \alpha$-reductase or to E2 by aromatase. Aromatization of androgens to estrogens occurs in adipose tissue muscle, bone and brain (9). Many of the masculinizing effects of endogenous testosterone until initiation of feminizing treatment during puberty and adult life will not be reverted despite partial or complete suppression of androgen levels. Therefore, in most cases, additional treatment is needed, which may include voice training, surgical intervention on the vocal cords, laser treatment of terminal hair growth and maybe facial surgery (1). Importantly, antiandrogen treatment will result in testicular atrophy and azoospermia within few months. After a longer treatment duration (2-3 years), the decrease in fertility is considered, at least partially, irreversible, therefore, sperm cryopreservation should be carefully discussed before the prescription of anti-androgen treatment $(21,22)$. In the case of orchiectomy, anti-androgen treatment can be stopped and spare the patient from the side effects of antiandrogen treatment. The timing of orchiectomy will very much depend on local traditions including the possibility for genital reconstruction surgery.

The choice of anti-androgen treatment will very much depend on national availability, pricing and financing of drugs (1). In Europe, the most commonly prescribed androgen-lowering medication for feminization is CPA. Spironolactone is commonly prescribed in the US where CPA is not available (1). GnRH-a is provided free of charge to transgender women by the National Health Service in the United Kingdom, whereas, for example, in Belgium, Denmark, and Australia, GnRH-a is provided by the hospital for puberty suppression only (23).

The mechanism for testosterone suppression differs between different anti-androgen treatments. In overview, anti-androgen treatments include androgen receptor antagonists (spironolactone and flutamide), whereas GnRH-a and progestogens suppress the hypothalamicpituitary-gonadal axis. CPA has a dual action on the androgen receptor and the hypothalamic-pituitarygonadal axis. 5-alfa reductase inhibitors block the conversion of testosterone to dihydrotestosterone.

Feminization and androgen suppression are the primary goals of anti-androgen treatment as part of GAHT. One Cochrane review in transgender women found no study regarding efficacy and safety of hormone therapy with antiandrogens or E2 alone, or in combination (20). One recent systematic review found four studies regarding the effects of different anti-androgen treatment modalities on testosterone levels in transgender women (23). The authors concluded that the addition of CPA, GnRH-a and progestin may be more effective than spironolactone or estradiol alone at suppressing the serum total testosterone concentration (23). The authors found no eligible studies regarding the effects of antiandrogens on breast development or facial and body hair reduction (23). Serum levels of testosterone may not be meaningful endpoints for feminization especially for androgen receptor antagonists (23). The recent review by Angus et al. (23) did not include 
a discussion regarding the safety and dosage of individual anti-androgen treatment modalities, and these issues will be further discussed in the present review.

\section{Cyproterone acetate (CPA)}

CPA inhibits the testosterone receptor and acts as synthetic progesterone (progestin), which results in the suppression of the hypothalamic-pituitary-gonadal axis. CPA is a part of oral contraceptives with an anti-androgen effect (G03HB01, containing $2 \mathrm{mg}$ CPA per tablet), which can be prescribed as second-line oral contraceptives to treat hirsutism in cisgender women. For transgender women, CPA has the benefit of being relatively cheap, and it is administered orally in contrast to GnRH-a (1). After oral ingestion, the maximal plasma concentration is reached after around $3 \mathrm{~h}$ and the turnover time is slow with plasma half time of 2-3 days. Therefore, CPA can also be administered every 2 nd or even every 3rd day.

CPA is a strong inhibitor of serum testosterone. A recent paper found significantly lower total testosterone concentrations $(0.8 \mathrm{nmol} / \mathrm{L}(0.6-1.20 \mathrm{nmol} / \mathrm{L}))$ during CPA in transgender women compared to testosterone levels during spironolactone $(2.0 \mathrm{nmol} / \mathrm{L} \quad(0.9-9.4$ $\mathrm{nmol} / \mathrm{L})$ and $\mathrm{E} 2$ alone $(10.5 \mathrm{nmol} / \mathrm{L}(4.9-17.2 \mathrm{nmol} / \mathrm{L})$ (24)). The median daily CPA dosage in the study was 50 $\mathrm{mg}$ (24). The progestin effect of CPA may improve breast development (1). However, as mentioned previously, no data are available regarding the feminizing effect of CPA alone in transgender women (23).

Several reservations may apply to the use of CPA. Observational studies in transgender women reported adverse lipid status (low HDL) during CPA $(25,26)$, and insulin resistance tended to increase during feminizing treatment including CPA (27), but findings could in part be explained by changed body composition with higher body weight and higher waist-hip ratio (27). Prolactin levels increased during CPA $(28,29)$, but serum prolactin levels normalized after stopping CPA (28). Prolactin is also an adipokine, and high prolactin levels outside reference intervals could infer higher metabolic risk (30). A possible association between high prolactin and breast cancer is undetermined (31). The risk of breast cancer increases during feminizing treatment, but most tumors are estrogen and progesterone receptor-positive (32). The known association between CPA therapy and the development of meningiomas (33) depends on cumulated dose (33). Thus international health authorities recommend that CPA should be used with caution to avoid the long-term risk of meningioma (34). At present, nine cases of meningioma have been described in transgender women, which is an elevated relative risk, but still very low absolute risk (35). In many centers, the dosage of CPA has been $25-50 \mathrm{mg} /$ day by the initiation of feminizing treatment, but in the future, the starting dosage of CPA could be reduced to $12.5 \mathrm{mg} /$ day and further down-titration of CPA can be considered after 6-12 months. CPA $10 \mathrm{mg} /$ day should be administered for no more than 2 years to keep below the maximal cumulative dose. Alternative anti-androgen use and earlier orchiectomy should be considered in order to avoid meningiomas during CPA. Furthermore, a healthy lifestyle should be supported to avoid weight gain and adverse metabolic profile during CPA treatment.

\section{Spironolactone}

Spironolactone is a non-selective mineralocorticoid and is an androgen and progesterone receptor antagonist. Spironolactone blocks the binding of dihydrotestosterone to its androgen receptor, thereby inhibiting androgen effects (24). The binding capacity of spironolactone to the androgen receptor is weaker than CPA (24). Spironolactone also acts as an inhibitor of $17 \alpha$-hydroxylase and 17,20lyase (enzymes in the testosterone biosynthetic pathway), which lowers testosterone to a small degree (24). The use of spironolactone for the treatment of hirsutism in cisgender women is well described, and spironolactone can be given as a part of oral contraceptives as drospirenone (4th generation oral contraceptive) (36).

In transgender women, spironolactone is administered orally as tablets in 25,50 , or $100 \mathrm{mg}$ doses. Few studies evaluated the feminizing effects of spironolactone treatment in transgender women. In a recent non-randomized Australian study (38 transgender women treated with spironolactone), the average prescribed dosage of spironolactone was $100 \mathrm{mg}$ (interquartile range) (87.5-200 mg). Serum testosterone levels during spironolactone treatment were significantly higher compared to CPA (2.0 vs $0.8 \mathrm{nmol} / \mathrm{L}$ ); however, data regarding feminizing physical characteristics and treatment satisfaction were not available $(24,26)$. As discussed by the authors, the mechanisms of actions differ between CPA and spironolactone and the level of total testosterone concentration may not be an applicable marker of feminization (24).

Several studies supported that spironolactone could improve metabolic risk compared to CPA. HDL levels 
increased (25) during spironolactone without any significant changes in prolactin $(25,26,37)$ and potassium levels $(26,38)$.

\section{GnRH-a}

GnRH-a inhibits the pituitary-gonadal axis and leads to suppressed gonadal sex hormone levels, whereas adrenal androgen production is kept intact. In children, GnRH-a is used for the treatment of central precocious puberty. In adults, GnRH-a is applied as a part of fertility treatment, treatment of endometriosis, and prostate cancer. GnRH-a is usually administered by depot injections, and the cost of treatment is relatively high. In many countries, GnRH-a is commonly prescribed to suppress endogenous puberty in transgender adolescents, whereas GnRH-a treatment is not commonly applied for treatment in adult transgender women (1) due to the high cost and other available treatments (1). As a result, the use of GnRH-a has mainly been studied in adolescent study populations. One study in transgender girls reported effective gonadal suppression after 3 months of GnRH-a treatment, resulting in nearly undetectable gonadotropins levels and decreased testosterone from $9.1 \mathrm{nmol} / \mathrm{L}$ to $1.0 \mathrm{nmol} / \mathrm{L}$ (39). The main concern is the long-term health consequences of gonadal suppression (40). Bone mineral density Z-scores remained below zero in transgender girls 3 years after treatment with combined GnRH-a and E2 (41). We are not aware of longterm studies on fracture risk following the suppression of puberty. Limited data are available in adult transgender female study populations regarding study outcomes of previous puberty blocking such as cardiovascular risk. A Trans Youth Care Research Network was established in the US with the aim to perform a longitudinal observational study in young transgender individuals starting puberty blockers compared to individuals starting GAHT without GnRH-a (42). Data from this study cohort showed that transgender women treated with GnRH-a+estrogen needed lower doses of estrogen to achieve desired physiologic changes compared to transgender women not using GnRH-a (43). However, the number of transgender women treated with GNRH-a was so far limited to only six, and spironolactone was used as an androgen blocker in the comparison group, which could have affected study outcomes (43). Administration of GnRH-a in early puberty will lead to underdevelopment of the penis, which can compromise future vaginoplasty (44). Furthermore, termination of puberty will lead to underdeveloped testes and semen production, which will compromise options for fertility preservation (45).

\section{$5 \alpha$-reductase inhibitors}

Finasteride and dutasteride are $5 \alpha$-reductase inhibitors, which inhibit the conversion of testosterone to the more active dihydrotestosterone. Furthermore, 5 $\alpha$-reductase inhibitors block the conversion of progesterone to dihydroprogesterone and deoxycorticosterone to dihydrodeoxycorticosterone (46). The use of $5 \alpha$ reductase inhibitors is prescribed in cisgender men for the treatment of benign prostate hypertrophia and sometimes for the treatment of androgenic hair loss, whereas the use of $5 \alpha$-reductase inhibitors in transgender women is controversial (46). Transgender women may request $5 \alpha$-reductase inhibitors to improve the anti-androgen effects of feminizing treatment, but no clinical studies supported their use. Especially when testosterone levels are already suppressed, as seen during CPA or spironolactone treatment, the benefit of $5 \alpha$-reductase inhibitors will probably be negligible. As recently discussed, testosterone levels could increase during treatment with $5 \alpha$-reductase inhibitors $(46,47)$. We are not aware of studies in transgender women regarding the effect of $5 \alpha$-reductase inhibitors on secondary female characteristics. In conclusion, treatment with $5 \alpha$-reductase inhibitors in transgender women is considered to be of no clinical benefit and is, therefore, not recommended.

\section{Flutamide}

Flutamide acts as a selective antagonist of the androgen receptor (AR) and is used for the treatment of prostate cancer. Testosterone levels are unchanged during flutamide treatment and due to the risk of hepatotoxic side effects, flutamide is not recommended for GAHT (1).

\section{Progesterone}

In themenstrual cycle, progesterone levels surge after ovulation, and the measurement of serum progesterone in the late menstrual cycle is applied to determine ovulatory cycles. The stimulatory effect of progesterone on female breast development is well described and progesterone promotes alveologenesis and ductal side branching (48). Progesterone (progestogen) therapy can be prescribed as the natural hormone or synthetic as progestins. Natural progesterone is used as a part of fertility treatment, and progestins are used in oral contraceptives.

In transgender women, the mechanism for a feminizing effect of progestogens is the inhibition of the hypothalamic-pituitary-gonadal axis and possibly 
improved breast development. As earlier discussed, feminizing treatment with CPA imply a considerable progestin effect. Therefore, a reduction of CPA dosage to a minimum may lead to a higher request for additional progesterone treatment. Breast development during progesterone treatment in transgender women has been investigated as a part of lactation induction, where transgender women were treated with high dosage progesterone and domperidone on top of usual GAHT (49). GAHT treatment protocols using medications with progestational properties did not result in a difference in the request for mammoplasty compared to treatment protocols without progestins (50). Due to limited evidence regarding breast development, progesterone treatment is currently not recommended in guidelines $(51,52)$.

The risk of side effects during progesterone treatment is debated. Information regarding the proliferative/antiproliferative effects of progesterone in breast cancer is conflicting (48). According to a recent review in transgender women, half of the diagnosed breast cancers were hormone-sensitive with positive progesterone receptor status in 5 of the 14 tested transgender women (53). Natural progesterone treatment may have fewer adverse effects on breast cancer risk than progestin (54). Mental health could be associated with progesterone/ estradiol levels $(55,56)$. Low luteal phase progesterone levels were associated with the peri-menstrual syndrome in cisgender women (57). Progestin treatment was associated with a higher risk of depression (58), whereas progesterone treatment decreased postpartum depression (59). Whether the progesterone/estradiol ratio is associated with mental health in transgender women is undetermined.

The risk of VTE is considered to be increased during progestogen treatment (60). Progestogens affect the tissue factor-dependent pathway of the coagulation cascade and could increase the levels of protein $S$ and fibrinogen (60). However, progestogens also affect the concentration of fibrinolytic factors, which questions the overall effect of progestogens on the turnover of fibrin (60). The effect of natural progesterone on the hemostatic system is sparsely examined (61). Fluid retention, weight gain and higher blood pressure are well-described side effects of progesterone treatment (62). Progesterone has a high affinity for the mineralocorticoid receptor and acts as a mineralocorticoid receptor antagonist $(62,63)$. Furthermore, inhibition of the enzyme 11beta-hydroxysteroid dehydrogenase 2 (11beta-HSD2) by progesterone and its metabolites results in decreased inactivation of cortisol and hence increased mineralocorticoid receptor binding by cortisol (62). In contrast, progesterone has been shown to suppress 11betaHSD1 activity in cultured human hepatocytes (63), which will decrease cortisol concentrations. Because of these contrasting effects of progesterone in different tissues, it is clear that only experimental testing can elucidate the in vivo effect of progesterone on mineralocorticoid signaling. We are not aware of studies regarding the possible effects of progesterone treatment on blood pressure, renal salt retention, renin/aldosterone ratio and cortisol metabolites in study populations of transgender women.

\section{Feminizing effects of GAHT}

\section{Breast development}

Breast development during different treatment regimens in transgender women was evaluated in few clinical studies. The European Network for the Investigation of Gender Incongruence (ENIGI) study is an ongoing collaboration of four centers (Amsterdam, Florence, Ghent, and Oslo) (64). Breast development was investigated in 329 transgender women (average age 28 years) after 1 year of feminizing treatment (65). Feminizing treatment included E2 tablets ( 2 to $6 \mathrm{mg}$ daily), E2 patches ( 0.05 to $0.1 \mathrm{mg} / 24 \mathrm{~h}$ twice weekly), or E2 gel (0.75 to $3 \mathrm{mg}$ daily) combined with CPA (10 to $100 \mathrm{mg}$ daily) or spironolactone (100 to $150 \mathrm{mg}$ daily). Transdermal E2 was advised in transgender women $>40$ years. The study reported modest breast development (mean change in breast circumference $+3.7 \mathrm{~cm}$ ), which occurred primarily within the first 6 months (65). Transdermal E2 resulted in faster increase in breast-chest difference until 6 months after initializing treatment. However, breast development after 1 year of feminizing treatment was comparable between oral and transdermal E2. No clinical or laboratory parameters predicted breast development (65). Most recently, de Blok et al. applied 3D imaging during 3 years of feminizing treatment in 69 transgender women and reported no associations between increase in breast volume and treatment regimen, serum E2 levels, age, BMI, and tobacco use (66). These results are in line with a controlled, retrospective case audit in transgender women seeking mammoplasty after at least 2 years of feminizing treatment (67). Transgender women were 39 years of age and had been treated with different hormonal regimens for 10 years in average. The type of estrogen use did not affect the request for mammoplasty (67). 


\section{Body composition}

The aim of GAHT is to obtain female body shape with fat redistribution from central to peripheral fat. A recent meta-analysis included 21 studies and showed that GAHT was associated with decreased waist-to-hip ratio, a rise in gynoid fat, and gain of total fat mass (68). Lean body mass (68) and muscle strength (69) were decreased during the initiation of GAHT, but muscle strength still remained higher compared to cisgender women during the first 3 years of GAHT (69). Interestingly, transgender women had lower lean body mass and higher fat mass than control males even before initiating GAHT (68). Several studies supported that GAHT could increase insulin resistance, but long-term studies are missing (68).

\section{Terminal hair growth (hirsutism)}

Quality of life is inversely associated with hirsutism in transgender women (70), but clinical studies regarding terminal hair growth during GAHT are limited. One study reported decreased hair growth and sebum production during GAHT and the decrease in hair shaft diameter reached its maximum at 4 months (71). Facial hair growth continued during GAHT, but at a slower rate (71). In accordance, it was reported that more than $90 \%$ of transgender women had a wish for hair removal (72).

\section{Other treatment effects of GAHT}

\section{Patient reported outcomes, depression and aggression}

The prevalence of depression and low quality of life is high in transgender study populations (73) and one of the more important aims of GAHT is to improve the quality of life. GAHT is considered beneficial for the quality of life and reduction of depression (74), but high-quality data are limited (75). Importantly, suicide rates remain high in transgender persons after GAHT (76). We are not aware of studies comparing individual treatment regimens regarding patient-reported outcomes. Changes in patientreported outcomes including mental health could be a valuable tool to determine and validate the effects of GAHT. Depression is more than twice as prevalent in cisgender women compared to cisgender men (77), and the interaction between estradiol and mental health has been investigated in cisgender study populations. A national Danish register-based study reported that the use of hormonal contraceptives in cisgender women was followed by increased prescription of antidepressants (58), but all oral contraceptives contained some form of progesterone. A Swedish register-based study found that the use of oral contraceptives was associated with a higher risk of suicidal behavior (78). The risk of depression could be mediated by fluctuating hormone levels as seen during puberty, post-partum, at perimenopause and after initiating oral contraceptives $(77,78)$. In analogy, in transgender women, the risk of depression could be highest after the initiation of feminizing treatment, and if dose reduction of E2 is necessary during aging or occurrence of intercurrent disease. Some transgender women may be more susceptible to psychiatric side effects of estrogen fluctuations (77). Monitoring of depressive symptoms and psychological support could be warranted during short-term changes in feminizing treatment regimen, whereas long-term stable treatment seems safer. Fluctuations of testosterone levels could also affect psychological wellbeing in transgender women in line with the findings in cisgender women, where irritability during the premenstrual phase was associated with testosterone levels (79). However, in long-term studies, testosterone levels were not associated with aggression in transgender study populations $(80,81)$.

\section{Sexual health}

In a questionnaire-based cross-sectional study in 214 transgender women, $62 \%$ reported decreased sexual desire after feminizing treatment and $73 \%$ never or rarely experienced spontaneous or responsive sexual desire (82). Four to six years after entering the ENIGI study, $26 \%$ of the transgender women reported difficulties in initiating and seeking sexual contact and $28 \%$ had difficulties achieving an orgasm (83). There were no significant differences in study outcomes between participants with or without intentions for genital surgery (83).

\section{Arterial cardiovascular disease (CVD)}

Epidemiological studies in transgender women reported an increased risk of acute myocardial infarction and stroke during feminizing treatment, whereas long-term, controlled studies regarding feminizing treatment and the risk of arterial CVD are lacking (84). In contrast, a systematic review and meta-analysis of cardiovascular outcomes in transgender individuals did not find an increased risk of myocardial infarction or stroke in transgender women, owing to the lack of reported outcomes from 29 eligible 
studies (85). Feminizing hormone therapy was associated with increased serum triglyceride levels of $31.9 \mathrm{mg} /$ dL (95\% CI, 3.9 to 59.9) in transgender women treated for $>24$ months with no changes in serum low-density lipoprotein or high-density lipoprotein (85). Of note, CVD is the main cause of death in cisgender persons, but, in general, coronary heart disease occurs years later in women compared to men (86). Premenopausal women are relatively protected against arterial CVD compared to age-matched men and high E2 levels were negatively associated to CVD in postmenopausal women (86). These findings suggest that endogenous and exogenous estrogens influence the risk of CVD in cisgender women. Findings regarding the higher risk of acute myocardial infarction and stroke during feminizing treatment confirm that CVD risk in transgender women is influenced by the known risk factors such as high BMI, smoking, sedentary lifestyle, hypertension, hypercholesterolemia or type 2 diabetes, but also the 'natal sex atheroma burden' (84). Cisgender men will tend to have a larger 'atheroma burden' at a given age compared to cisgender women. Therefore, the age of initiation of feminizing treatment in transgender women is important regarding the duration of exposure to potential risk factors. Furthermore, age and timing are important with respect to estrogen therapy, as estrogens may be vasoprotective in women without atherosclerosis as opposed to women with later stages of atherosclerosis (84). Hypertension is an important risk factor for CVD, which may be relatively easily modified (86), and E2 protected against hypertension in experimental animal studies (87).

\section{Venous thromboembolism (VTE)}

Risk of VTE occurrence in transgender women is likely increased given the known prothrombotic actions of estrogen (84). In accordance, the incidence of VTE was increased in transgender women with 2- and 8-year risk differences of 4.1 (95\% CI, 1.6-6.7) and 16.7 (6.4-27.5) per 1000 persons relative to cisgender men and 3.4 (1.15.6) and 13.7 (4.1-22.7) relative to cisgender women (88). Measurement of coagulation markers confirmed procoagulant changes during the initiation of GAHT (89). Most transgender women need life-long E2 therapy, and aging is a major risk factor for VTE development (90, 91). Other risk factors for VTE include BMI $>25 \mathrm{~kg} / \mathrm{m}^{2}$, genetic factors and previous VTE $(90,91)$. The route of estrogen administration affects the risk of VTE $(89,91)$. Oral E2 changes hemostatic variables in a pro-thrombotic direction in contrast to transdermal E2, which was similar to placebo in a recent meta-analysis (91). Hepatic firstpass effect of oral E2 negatively impacts the synthesis of coagulation proteins, but other factors play a role $(91,92)$. At present, oral E2 is not recommended in transgender women with a high risk of VTE, and a change to dermal E2 administration should be discussed around the age of 40 years in all transgender women (1). Adding synthetic progesterone, including $\mathrm{CPA}$, to E2 therapy further increases the risk of VTE (see below) (91). Anticoagulation therapy following a thrombotic event in transgender women can be considered (1), but there are no long-term studies to guide GAHT in high-risk transgender women and following a thrombotic event.

\section{Bone health}

Sex hormones are essential for osteoblast function, and eugonadal men and premenopausal women are relatively protected against osteoporosis. Testosterone levels will decrease during feminizing treatment, but sufficient treatment with E2 could maintain bone health (93). A recent meta-analysis included 13 studies (392 transgender women) (94). Bone mineral density at the lumbar spine significantly increased after the initiation of feminizing treatment at 12 months $\left(0.04 \mathrm{~g} / \mathrm{cm}^{2} ; 95 \%\right.$ CI $0.03-0.06$ $\left.\mathrm{g} / \mathrm{cm}^{2}\right)$ and at 24 months $\left(0.06 \mathrm{~g} / \mathrm{cm}^{2} ; 0.04-0.08 \mathrm{~g} / \mathrm{cm}^{2}\right)$, which is in the range considered clinically significant (94). Hip bone mineral density was unchanged (94). The review included studies until 2015 and various estrogen regimens were applied, which could have affected study results (94). More recently, the ENIGI study addressed bone turnover markers during a contemporary E2 regimen in 121 transgender women (95). Bone resorption markers decreased by $10-11 \%$ after 1 year of treatment, which supported protected bone health (95). One recent study reported higher fracture risk in older transgender women (>50 years) compared to age-matched reference cisgender men, but fracture risk resembled age-matched cisgender women (96). However, transgender women aged $<50$ years tended to have a higher fracture risk compared with age-matched reference cisgender women (96). More prospective data on bone mineral density and fractures in transgender women are awaited. Importantly, a high percentage of low bone mineral density and hypovitaminosis D was found prior to GAHT (97). Therefore, evaluation of bone mineral density and $25 \mathrm{OH}$ vitamin D before starting the feminizing treatment may be considered in high-risk individuals $(93,94)$. It 

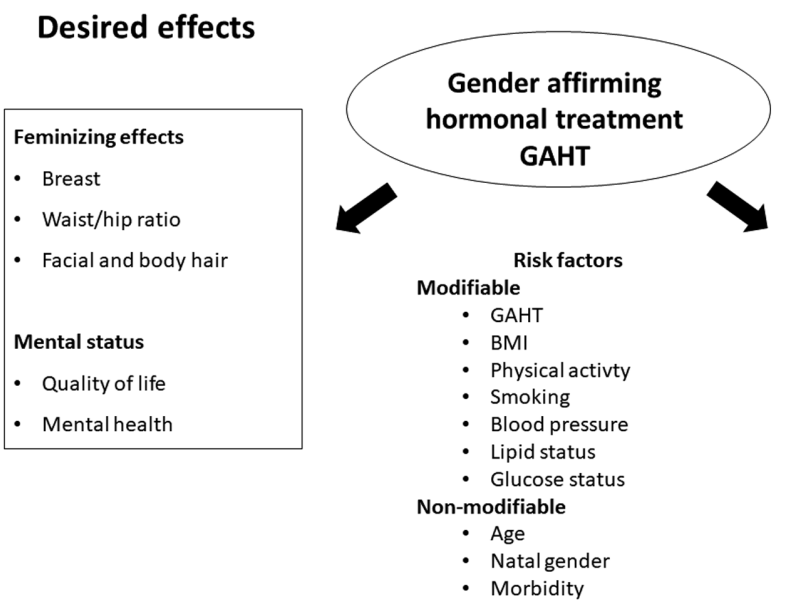

is important to recognize that suboptimal medicine compliance in transgender women is associated with low bone mass (97).

\section{Cancer risk}

GAHT could affect the risk of hormone-sensitive cancer types including breast cancer and prostate cancer. Furthermore, the gender difference is described for several other cancer types in cisgender people, which suggests an impact of sex hormones. In a recent register-based study, cancer diagnosis at later stages in transgender persons and worse survival for many cancer types was partly explained through existing barriers to access the healthcare system (98).

Breast tissue has estrogen receptors and the risk of breast cancer is higher in cisgender women compared to cisgender men. Incidence rates of breast cancer in transgender women were lower than in cisgender women (incidence ratio 0.3) in a recent retrospective Dutch study of 2260 transgender women (median duration of feminizing treatment, 13 years) (32). The risk of breast cancer increased toward cisgender female levels during feminizing treatment and the characteristics of breast cancer resembled a female pattern $(32,99)$. These results suggest that breast cancer screening guidelines for cisgender women are sufficient for transgender women on feminizing treatment (32). The study included the whole spectrum of estrogen treatments and data could not be split up into subgroups of treatment modalities (32). The median age at breast cancer diagnosis was 50 years (interquartile range 43-55 years). However, a few breast cancer cases were diagnosed at age 30 years (32), which indicates that transgender women at particular risk (such as BRCA positive persons) should attend specific screening programs in accordance with those for cisgender women (99).

Prostate cancer is affected by testosterone levels and data support that antiandrogen treatment in transgender women results in a much lower risk of prostate cancer (standardized incidence ratio 0.20, 95\% CI 0.08-0.42) (100). However, the presence of estrogen receptor $\alpha$ cells in a case report of prostate cancer raised concern for a possible contributing role of exogenous estrogen therapy in tumorigenesis (101).

Colorectal cancer is more prevalent in men compared to women. In postmenopausal women, E2 replacement therapy and the consumption of soy reduced the risk of colorectal cancer (102). The protective effect of E2 on colorectal cancer is mediated by the estrogen receptor subtype $\beta$ (102). The putative protective effect of estrogen therapy on the risk of colon cancer in transgender women is undetermined.

Esophageal adenocarcinoma has a male to female ratio of 9:1, and the time of diagnosis is postponed for a median of 16 years in women compared to men (103). This suggests that estrogens may protect and/or testosterone exposure may increase the risk of esophageal adenocarcinoma. However, men with higher testosterone levels had a significantly lower risk of esophageal adenocarcinoma and E2 levels were not associated with cancer risk (104). Age, BMI and smoking are important risk factors for esophageal adenocarcinoma (103) and several other cancer types.

Obesity and smoking are relative contraindications for GAHT, and lifestyle intervention is often a part of good clinical practice of transgender care. Therefore, the individual role of exogenous estrogen for cancer risk in transgender women will be difficult to determine. 


\section{Monitoring GAHT in transgender care}

Objective measurement of breast development (breastchest difference or 3D imaging) may not be routinely performed in the clinic, and more research is needed to determine the best marker for feminization in study cohorts of transgender women. Instead, serum E2 is often used to monitor the feminizing effect of GAHT. According to recent guidelines for hormonal treatment in transgender persons, the goal of feminizing treatment is to reach a physiologic serum level of $\mathrm{E} 2$ and testosterone for similar-aged cisgender women, that is, serum E2 level in the upper follicular range $(0.4-0.6 \mathrm{mmol} / \mathrm{L})$ and a low serum testosterone $(3,4)$. Unfortunately, there are no general recommendations regarding the timing of blood sampling in relation to E2 administration (105). Timing of blood sampling should reflect the average level of E2, which implies that sampling should be performed halfway between two E2 administrations. Contamination of the blood sample by dermally applied hormone should be avoided. Ideally, the timing of blood sampling and drug administration should be similar across different sampling points to ensure that longitudinal hormone results are minimally influenced by absorption, metabolism, and user-related discrepancies. In daily clinics, this will be at least challenging or often impossible. Furthermore, the gold standard for E2 measurement, mass spectrometry, is not widely available. The use of serum E2 as a marker of feminization contrasts studies reporting no significant association between E2 levels and breast development $(65,66,67)$. However, serum E2 was measured by different hormone assays, and the timing of blood sampling after E2 administration was not standardized, which could have affected study results $(65,66,67)$. According to Table 1, E1 measurements could be relevant during oral E2 treatment, but this hypothesis remains to be tested. Recently, polymorphisms of the estrogen receptor $\alpha$ gene were associated with gender incongruence in transgender men, whereas no association was found in transgender women (106). In postmenopausal women, variations in the estrogen receptors affected individual variation in treatment effects of E2 (107), and further studies regarding variations in the estrogen receptor are requested in transgender study populations.

\section{Contraindications and reservations for E2 treatment in transgender women}

Long-term risks regarding cardiovascular health and cancer should be discussed with the patient before initiating E2 treatment (Fig. 1). Clinical and laboratory workup at baseline should assess BMI, blood pressure, lipid profile, and HbA1c. BMI and smoking are important modifiable risk factors for cardiovascular disease and several cancer types. Obesity and smoking could be considered relative contraindications for GAHT, but cutoff levels for BMI are not available. Of course, lifestyle intervention is considered part of good clinical practice if needed. In these patients, the preferred use of dermal E2 above the age of 40 years is discussed previously. But, overall, feminizing treatment can be considered safe, and prospective metabolic risk screening can follow current guidelines for cisgender persons (108).

\section{Conclusion}

GAHT for transgender women should be tailored to the individual patient. In normal-weight younger persons, the a priori general health is usually good and the choice of treatment can be done quite freely. However, as age, $\mathrm{BMI}$ and cardio-metabolic risk factors increase, feminizing treatment should be prescribed under consideration of risk factors. Lifestyle factors should always be discussed as a part of the outpatient consultation. There is a need for clinical studies exploring the optimal treatment of transgender women. Overall, feminization treatment can be considered as safe, but hormonal treatment may need adaptations if health risk factors develop over time. Future studies should add patient-reported outcomes including satisfaction with breast development as these outcomes may not correlate with serum measures of E2 and testosterone levels.

Declaration of interest

The authors declare that there is no conflict of interest that could be perceived as prejudicing the impartiality of this review.

\section{Funding}

This work did not receive any specific grant from any funding agency in the public, commercial, or not-for-profit sector.

\section{References}

1 T’Sjoen G, Arcelus J, Gooren L, Klink DT \& Tangpricha V. Endocrinology of transgender medicine. Endocrine Reviews 201940 97-117. (https://doi.org/10.1210/er.2018-00011)

2 Burgwal A, Gvianishvili N, Hård V, Kata J, García Nieto I, Orre C, Smiley A, Vidić J \& Motmans J. Health disparities between binary and non binary trans people: a community-driven survey. International Journal of Transgenderism 201920 218-229. (https://doi.org/10.1080/ 15532739.2019.1629370) 
3 Hembree WC, Cohen-Kettenis PT, Gooren L, Hannema SE, Meyer WJ, Murad MH, Rosenthal SM, Safer JD, Tangpricha V \& T'Sjoen GG. Endocrine treatment of gender-dysphoric/gender-incongruent persons: an Endocrine Society clinical practice guideline. Journal of Clinical Endocrinology and Metabolism 2017102 3869-3903. (https:// doi.org/10.1210/jc.2017-01658)

4 T'Sjoen G, Arcelus J, De Vries ALC, Fisher AD, Nieder TO, Özer M \& Motmans J. European Society for Sexual Medicine position statement 'assessment and hormonal management in adolescent and adult trans people, with attention for sexual function and satisfaction'. Journal of Sexual Medicine 202017 570-584. (https://doi. org/10.1016/j.jsxm.2020.01.012)

5 Randolph Jr JF. Gender-affirming hormone therapy for transgender females. Clinical Obstetrics and Gynecology 201861 705-721. (https:// doi.org/10.1097/GRF.0000000000000396)

6 Marks DH, Peebles JK \& Dommasch E. Hair reduction for transgender persons: what dermatologists should know and how they can help. JAMA Dermatology 2019155 525-526. (https://doi.org/10.1001/ jamadermatol.2019.0149)

7 Yeung H, Kahn B, Ly BC \& Tangpricha V. Dermatologic conditions in transgender populations. Endocrinology and Metabolism Clinics of North America 201948 429-440. (https://doi.org/10.1016/j. ecl.2019.01.005)

8 Fardoun M, Dehaini H, Shaito A, Mesmar J, El-Yazbi A, Badran A, Beydoun E \& Eid AH. The hypertensive potential of estrogen: an untold story. Vascular Pharmacology 2020124 106600. (https://doi. org/10.1016/j.vph.2019.106600)

9 Russell N \& Grossmann M. MECHANISMS IN ENDOCRINOLOGY: Estradiol as a male hormone. European Journal of Endocrinology 2019 181 R23-R43. (https://doi.org/10.1530/EJE-18-1000)

10 Smith GI, Yoshino J, Reeds DN, Bradley D, Burrows RE, Heisey HD, Moseley AC \& Mittendorfer B. Testosterone and progesterone, but not estradiol, stimulate muscle protein synthesis in postmenopausal women. Journal of Clinical Endocrinology and Metabolism 201499 256-265. (https://doi.org/10.1210/jc.2013-2835)

11 Sidelmann JJ, Jespersen J, Andersen LF, Skouby SO \& Prospective Collaborative Danish Climacteric Study. Hormone replacement therapy and hypercoagulability. Results from the prospective Collaborative Danish Climacteric Study. BJOG 2003110 541-547. (https://doi.org/10.1046/j.1471-0528.2003.02165.x)

12 Selby P, McGarrigle HH \& Peacock M. Comparison of the effects of oral and transdermal oestradiol administration on oestrogen metabolism, protein synthesis, gonadotrophin release, bone turnover and climacteric symptoms in postmenopausal women. Clinical Endocrinology 198930 241-249. (https://doi. org/10.1111/j.1365-2265.1989.tb02232.x)

13 Streed Jr CG, Harfouch O, Marvel F, Blumenthal RS, Martin SS \& Mukherjee M. Cardiovascular disease among transgender adults receiving hormone therapy: a narrative review. Annals of Internal Medicine 2017167 256-267. (https://doi.org/10.7326/M17-0577)

14 Gooren L \& Lips P. Conjectures concerning cross-sex hormone treatment of aging transsexual persons. Journal of Sexual Medicine 201411 2012-2019. (https://doi.org/10.1111/jsm.12563)

15 Gooren LJ \& T'Sjoen G. Endocrine treatment of aging transgender people. Reviews in Endocrine and Metabolic Disorders 201819 253-262. (https://doi.org/10.1007/s11154-018-9449-0)

16 Asscheman H, Giltay EJ, Megens JA, de Ronde WP, van Trotsenburg MA \& Gooren LJ. A long-term follow-up study of mortality in transsexuals receiving treatment with cross-sex hormones. European Journal of Endocrinology 2011164 635-642. (https://doi.org/10.1530/EJE-10-1038)

17 Sierra-Ramírez JA, Lara-Ricalde R, Lujan M, Velázquez-Ramírez N, Godínez-Victoria M, Hernádez-Munguía IA, Padilla A \& GarzaFlores J. Comparative pharmacokinetics and pharmacodynamics after subcutaneous and intramuscular administration of medroxyprogesterone acetate $(25 \mathrm{mg})$ and estradiol cypionate (5 mg). Contraception 201184 565-570. (https://doi.org/10.1016/j. contraception.2011.03.014)

18 Gass MS, Rebar RW, Cuffie-Jackson C, Cedars MI, Lobo RA, Shoupe D, Judd HL, Buyalos RP \& Clisham PR. A short study in the treatment of hot flashes with buccal administration of 17-beta estradiol. Maturitas 200449 140-147. (https://doi.org/10.1016/j. maturitas.2003.12.004)

19 Salehian B, Wang C, Alexander G, Davidson T, McDonald V, Berman N, Dudley RE, Ziel F \& Swerdloff RS. Pharmacokinetics, bioefficacy, and safety of sublingual testosterone cyclodextrin in hypogonadal men: comparison to testosterone enanthate - a clinical research center study. Journal of Clinical Endocrinology and Metabolism 199580 3567-3575. (https://doi.org/10.1210/jcem.80.12.8530600)

20 Haupt C, Henke M, Kutschmar A, Hauser B, Baldinger S, Saenz SR $\&$ Schreiber G. Antiandrogen or estradiol treatment or both during hormone therapy in transitioning transgender women. Cochrane Database of Systematic Reviews 202011 CD013138. (https://doi. org/10.1002/14651858.CD013138.pub2)

21 De Roo C, Tilleman K, T'Sjoen G \& De Sutter P. Fertility options in transgender people. International Review of Psychiatry 201628 112-119. (https://doi.org/10.3109/09540261.2015.1084275)

22 Vereecke G, Defreyne J, Van Saen D, Collet S, Van Dorpe J, T'Sjoen G \& Goossens E. Characterisation of testicular function and spermatogenesis in transgender women. Human Reproduction 202136 5-15. (https://doi.org/10.1093/humrep/deaa254)

23 Angus LM, Nolan BJ, Zajac JD \& Cheung AS. A systematic review of anti-androgens and feminisation in transgender women. Clinical Endocrinology 202094 743-752.

24 Angus L, Leemaqz S, Ooi O, Cundill P, Silberstein N, Locke P, Zajac JD $\&$ Cheung AS. Cyproterone acetate or spironolactone in lowering testosterone concentrations for transgender individuals receiving oestradiol therapy. Endocrine Connections 20198 935-940. (https:// doi.org/10.1530/EC-19-0272)

25 Fung R, Hellstern-Layefsky M, Tastenhoye C, Lega I \& Steele L. Differential effects of cyproterone acetate vs spironolactone on serum high-density lipoprotein and prolactin concentrations in the hormonal treatment of transgender women. Journal of Sexual Medicine 201613 1765-1772. (https://doi.org/10.1016/j.jsxm.2016.09.012)

26 Sofer Y, Yaish I, Yaron M, Bach MY, Stern N \& Greenman Y. Differential endocrine and metabolic effects of testosterone suppressive agents in transgender women. Endocrine Practice 202026 883-890. (https://doi.org/10.4158/EP-2020-0032)

27 Shadid S, Abosi-Appeadu K, De Maertelaere AS, Defreyne J, Veldeman L, Holst JJ, Lapauw B, Vilsbøll T \& T'Sjoen G. Effects of gender-affirming hormone therapy on insulin sensitivity and incretin responses in transgender people. Diabetes Care 202043 411-417. (https://doi.org/10.2337/dc19-1061)

28 Defreyne J, Nota N, Pereira C, Schreiner T, Fisher AD, den Heijer M $\&$ T'Sjoen G. Transient elevated serum prolactin in trans women is caused by cyproterone acetate treatment. LGBT Health 20174 328-336. (https://doi.org/10.1089/lgbt.2016.0190)

29 Nota NM, Dekker MJHJ, Klaver M, Wiepjes CM, van Trotsenburg MA, Heijboer AC \& den Heijer M. Prolactin levels during short- and long-term cross-sex hormone treatment: an observational study in transgender persons. Andrologia 201749 e12666. (https://doi. org/10.1111/and.12666)

30 Andersen M \& Glintborg D. Metabolic syndrome in hyperprolactinemia. Frontiers of Hormone Research 201849 29-47. (https://doi.org/10.1159/000486000)

31 De Hert M, Peuskens J, Sabbe T, Mitchell AJ, Stubbs B, Neven P, Wildiers H \& Detraux J. Relationship between prolactin, breast cancer risk, and antipsychotics in patients with schizophrenia: a critical review. Acta Psychiatrica Scandinavica 2016133 5-22. (https:// doi.org/10.1111/acps.12459)

32 de Blok CJM, Wiepjes CM, Nota NM, van Engelen K, Adank MA, Dreijerink KMA, Barbé E, Konings IRHM \& den Heijer M. Breast 
cancer risk in transgender people receiving hormone treatment: nationwide cohort study in the Netherlands. BMJ 201936511652. (https://doi.org/10.1136/bmj.11652)

33 Nota NM, Wiepjes CM, de Blok CJM, Gooren LJG, Peerdeman SM, Kreukels BPC \& den Heijer M. The occurrence of benign brain tumours in transgender individuals during cross-sex hormone treatment. Brain 2018141 2047-2054. (https://doi.org/10.1093/ brain/awy108)

34 (available at: https://www.ema.europa.eu/en/medicines/human/refer rals/cyproterone-containing-medicinal-products)

35 Mancini I, Rotilio A, Coati I, Seracchioli R, Martelli V \& Meriggiola MC. Presentation of a meningioma in a transwoman after nine years of cyproterone acetate and estradiol intake: case report and literature review. Gynecological Endocrinology 201834 456-459. (https://doi.org/10.1080/09513590.2017.1395839)

36 Barrionuevo P, Nabhan M, Altayar O, Wang Z, Erwin PJ, Asi N, Martin KA \& Murad MH. Treatment options for hirsutism: a systematic review and network meta-analysis. Journal of Clinical Endocrinology and Metabolism 2018103 1258-1264. (https://doi. org/10.1210/jc.2017-02052)

37 Bisson JR, Chan KJ \& Safer JD. Prolactin levels do not rise AMONG transgender women treated WITH estradiol and spironolactone. Endocrine Practice 201824 646-651. (https://doi.org/10.4158/ EP-2018-0101)

38 Millington K, Liu E \& Chan YM. The utility of potassium monitoring in gender-diverse adolescents taking spironolactone. Journal of the Endocrine Society 20193 1031-1038. (https://doi.org/10.1210/js.201900030)

39 Schagen SE, Cohen-Kettenis PT, Delemarre-van de Waal HA \& Hannema SE. Efficacy and safety of gonadotropin-releasing hormone agonist treatment to suppress puberty in gender dysphoric adolescents. Journal of Sexual Medicine 201613 1125-1132. (https:// doi.org/10.1016/j.jsxm.2016.05.004)

40 Hruz PW. Deficiencies in scientific evidence for medical management of gender dysphoria. Linacre Quarterly 202087 34-42. (https://doi. org/10.1177/0024363919873762)

41 Schagen SEE, Wouters FM, Cohen-Kettenis PT, Gooren LJ \& Hannema SE. Bone development in transgender adolescents treated with GnRH analogues and subsequent gender-affirming hormones. Journal of Clinical Endocrinology and Metabolism 2020105 e4252-e4263. (https://doi.org/10.1210/clinem/dgaa604)

42 Olson-Kennedy J, Chan YM, Rosenthal S, Hidalgo MA, Chen D, Clark L, Ehrensaft D, Tishelman A \& Garofalo R. Creating the trans youth research network: a collaborative research endeavor. Transgender Health 20194 304-312. (https://doi.org/10.1089/ trgh.2019.0024)

43 Jensen RK, Jensen JK, Simons LK, Chen D, Rosoklija I \& Finlayson CA. Effect of concurrent gonadotropin-releasing hormone agonist treatment on dose and side effects of gender-affirming hormone therapy in adolescent transgender patients. Transgender Health 20194 300-303. (https://doi.org/10.1089/trgh.2018.0061)

44 Khatchadourian K, Amed S \& Metzger DL. Clinical management of youth with gender dysphoria in Vancouver. Journal of Pediatrics 2014 164 906-911. (https://doi.org/10.1016/j.jpeds.2013.10.068)

45 Mattawanon N, Spencer JB, Schirmer 3rd DA \& Tangpricha V. Fertility preservation options in transgender people: a review. Reviews in Endocrine and Metabolic Disorders 201819 231-242. (https://doi. org/10.1007/s11154-018-9462-3)

46 Irwig MS. Is there a role for $5 \alpha$-reductase inhibitors in transgender individuals? Andrology 2020. (https://doi.org/10.1111/andr.12881)

47 Leinung MC, Feustel PJ \& Joseph J. Hormonal treatment of transgender women with oral estradiol. Transgender Health 20183 74-81. (https://doi.org/10.1089/trgh.2017.0035)

48 Lamb CA, Fabris VT \& Lanari C. Progesterone and breast. Best Practice and Research: Clinical Obstetrics and Gynaecology 202069 85-94. (https://doi.org/10.1016/j.bpobgyn.2020.04.001)
49 Wamboldt R, Shuster S \& Sidhu BS. Lactation induction in a transgender woman wanting to breastfeed: case report. Journal of Clinical Endocrinology and Metabolism 2021106 e2047-e2052. (https://doi.org/10.1210/clinem/dgaa976)

50 Wierckx K, Gooren L \& T'Sjoen G. Clinical Review: Breast development in trans women receiving cross-sex hormones. Journal of Sexual Medicine 201411 1240-1247. (https://doi.org/10.1111/ jsm.12487)

51 Prior JC. Progesterone is important for transgender women's therapyapplying evidence for the benefits of progesterone in ciswomen. Journal of Clinical Endocrinology and Metabolism 2019104 1181-1186. (https://doi.org/10.1210/jc.2018-01777)

52 Iwamoto SJ, T'Sjoen G, Safer JD, Davidge-Pitts CJ, Wierman ME, Glodowski MB \& Rothman MS. Letter to the Editor: 'Progesterone is important for transwomen's therapy-applying evidence for the benefits of progesterone in ciswomen'. Journal of Clinical Endocrinology and Metabolism 2019104 3127-3128.

53 Hartley RL, Stone JP \& Temple-Oberle C. Breast cancer in transgender patients: a systematic review. Part 1: male to female. European Journal of Surgical Oncology 201844 1455-1462. (https://doi.org/10.1016/j. ejso.2018.06.035)

54 Asi N, Mohammed K, Haydour Q, Gionfriddo MR, Vargas OL, Prokop LJ, Faubion SS \& Murad MH. Progesterone vs. synthetic progestins and the risk of breast cancer: a systematic review and meta-analysis. Systematic Reviews 20165 121. (https://doi. org/10.1186/s13643-016-0294-5)

55 Seligowski AV, Hurly J, Mellen E, Ressler KJ \& Ramikie TS. Translational studies of estradiol and progesterone in fear and PTSD. European Journal of Psychotraumatology 202011 1723857. (https://doi. org/10.1080/20008198.2020.1723857)

56 Bristot G, Ascoli B, Gubert C, Panizzutti B, Kapczinski F \& Rosa AR. Progesterone and its metabolites as therapeutic targets in psychiatric disorders. Expert Opinion on Therapeutic Targets 201418 679-690. (https://doi.org/10.1517/14728222.2014.897329)

57 Roomruangwong C, Carvalho AF, Comhaire F \& Maes M. Lowered plasma steady-state levels of progesterone combined with declining progesterone levels during the luteal phase predict peri-menstrual syndrome and its major subdomains. Frontiers in Psychology 201910 2446. (https://doi.org/10.3389/fpsyg.2019.02446)

58 Skovlund CW, Mørch LS, Kessing LV \& Lidegaard Ø. Association of hormonal contraception With depression. JAMA Psychiatry 201673 1154-1162. (https://doi.org/10.1001/jamapsychiatry.2016.2387)

59 Trifu S, Vladuti A \& Popescu A. The neuroendocrinological aspects of pregnancy and postpartum depression. Acta Endocrinologica 201915 410-415. (https://doi.org/10.4183/aeb.2019.410)

60 Skouby SO \& Sidelmann JJ. Impact of progestogens on hemostasis. Hormone Molecular Biology and Clinical Investigation 201837 20180041 . (https://doi.org/10.1515/hmbci-2018-0041)

61 Canonico M. Hormone therapy and hemostasis among postmenopausal women: a review. Menopause 201421 753-762. (https://doi.org/10.1097/GME.0000000000000296)

62 Quinkler M, Diederich S, Bahr V \& Oelkers W. The role of progesterone metabolism and androgen synthesis in renal blood pressure regulation. Hormone and Metabolic Research 200436 381-386. (https://doi.org/10.1055/s-2004-814572)

63 Baker ME \& Katsu Y. Progesterone: an enigmatic ligand for the mineralocorticoid receptor. Biochemical Pharmacology 2020177 113976. (https://doi.org/10.1016/j.bcp.2020.113976)

64 Dekker MJ, Wierckx K, Van Caenegem E, Klaver M, Kreukels BP, Elaut E, Fisher AD, van Trotsenburg MA, Schreiner T, den Heijer M et al. A European Network for the investigation of gender incongruence: endocrine part. Journal of Sexual Medicine 201613 994-999. (https://doi.org/10.1016/j.jsxm.2016.03.371)

65 de Blok CJM, Klaver M, Wiepjes CM, Nota NM, Heijboer AC, Fisher AD, Schreiner T, T'Sjoen G \& den Heijer M. Breast development in transwomen after 1 year of cross-sex hormone 
therapy: results of a prospective multicenter study. Journal of Clinical Endocrinology and Metabolism 2018103 532-538. (https://doi. org/10.1210/jc.2017-01927)

66 de Blok CJM, Dijkman BAM, Wiepjes CM, Staphorsius AS, Timmermans FW, Smit JM, Dreijerink KMA \& den Heijer M. Sustained breast development and breast anthropometric changes in three years gender-affirming hormone treatment. Journal of Clinical Endocrinology and Metabolism 2021106 e782-e790. (https://doi. org/10.1210/clinem/dgaa841)

67 Seal LJ, Franklin S, Richards C, Shishkareva A, Sinclaire C \& Barrett J. Predictive markers for mammoplasty and a comparison of side effect profiles in transwomen taking various hormonal regimens. Journal of Clinical Endocrinology and Metabolism 201297 4422-4428. (https:// doi.org/10.1210/jc.2012-2030)

68 Spanos C, Bretherton I, Zajac JD \& Cheung AS. Effects of genderaffirming hormone therapy on insulin resistance and body composition in transgender individuals: a systematic review. World Journal of Diabetes 202011 66-77. (https://doi.org/10.4239/wjd.v11. i3.66)

69 Harper J, O'Donnell E, Sorouri Khorashad B, McDermott H \& Witcomb GL. How does hormone transition in transgender women change body composition, muscle strength and haemoglobin? Systematic review with a focus on the implications for sport participation. British Journal of Sports Medicine 2021. (https://doi. org/10.1136/bjsports-2020-103106)

70 Ristori J, Cocchetti C, Castellini G, Pierdominici M, Cipriani A, Testi D, Gavazzi G, Mazzoli F, Mosconi M, Meriggiola MC et al. Hormonal treatment effect on sexual distress in transgender persons: 2-year follow-up data. Journal of Sexual Medicine 202017 142-151. (https://doi.org/10.1016/j.jsxm.2019.10.008)

71 Giltay EJ \& Gooren LJ. Effects of sex steroid deprivation/ administration on hair growth and skin sebum production in transsexual males and females. Journal of Clinical Endocrinology and Metabolism 200085 2913-2921. (https://doi.org/10.1210/ jcem.85.8.6710)

72 Bradford NJ, Rider GN \& Spencer KG. Hair removal and psychological well-being in transfeminine adults: associations with gender dysphoria and gender euphoria. Journal of Dermatological Treatment 2019 In press. (https://doi.org/10.1080/09546634.2019.168 7823)

73 Motmans J, Meier P, Ponnet K \& T'Sjoen G. Female and male transgender quality of life: socioeconomic and medical differences. Journal of Sexual Medicine 20129 743-750. (https://doi.org/10.1111/ j.1743-6109.2011.02569.x)

74 Aldridge Z, Patel S, Guo B, Nixon E, Pierre Bouman W, Witcomb GL $\&$ Arcelus J. Long-term effect of gender-affirming hormone treatment on depression and anxiety symptoms in transgender people: a prospective cohort study. Andrology 2020 In press. (https://doi. org/10.1111/andr.12884)

75 Baker KE, Wilson LM, Sharma R, Dukhanin V, McArthur K \& Robinson KA. Hormone therapy, mental health, and quality of life among transgender people: a systematic review. Journal of the Endocrine Society 20215 bvab011. (https://doi.org/10.1210/jendso/ bvab011)

76 Liu RT, Sheehan AE, Walsh RFL, Sanzari CM, Cheek SM \& Hernandez EM. Prevalence and correlates of non-suicidal selfinjury among lesbian, gay, bisexual, and transgender individuals: a systematic review and meta-analysis. Clinical Psychology Review 2019 74 101783. (https://doi.org/10.1016/j.cpr.2019.101783)

77 Frokjaer VG. Pharmacological sex hormone manipulation as a risk model for depression. Journal of Neuroscience Research 202098 1283-1292. (https://doi.org/10.1002/jnr.24632)

78 Edwards AC, Lönn SL, Crump C, Mościcki EK, Sundquist J, Kendler KS \& Sundquist K. Oral contraceptive use and risk of suicida behavior among young women. Psychologie Medicale 2020 In press. (https://doi.org/10.1017/S0033291720003475)
79 Eriksson E, Sundblad C, Lisjö P, Modigh K \& Andersch B. Serum levels of androgens are higher in women with premenstrual irritability and dysphoria than in controls. Psychoneuroendocrinology 199217 195-204. (https://doi.org/10.1016/0306-4530(92)90058-f)

80 Kristensen TT, Christensen LL, Frystyk J, Glintborg D, T’Sjoen G, Roessler KK \& Andersen MS. Effects of testosterone therapy on constructs related to aggression in transgender men: a systematic review. Hormones and Behavior 2021128 104912. (https://doi. org/10.1016/j.yhbeh.2020.104912)

81 Defreyne J, T'Sjoen G, Bouman WP, Brewin N \& Arcelus J. Prospective evaluation of self-reported aggression in transgender persons. Journal of Sexual Medicine 201815 768-776. (https://doi.org/10.1016/j. jsxm.2018.03.079)

82 Wierckx K, Elaut E, Van Hoorde B, Heylens G, De Cuypere G, Monstrey S, Weyers S, Hoebeke P \& T'Sjoen G. Sexual desire in trans persons: associations with sex reassignment treatment. Journal of Sexual Medicine 201411 107-118. (https://doi.org/10.1111/ jsm.12365)

83 Kerckhof ME, Kreukels BPC, Nieder TO, Becker-Hébly I, van de Grift TC, Staphorsius AS, Köhler A, Heylens G \& Elaut E. Prevalence of sexual dysfunctions in transgender persons: results from the ENIGI follow-up study. Journal of Sexual Medicine 201916 2018-2029. (https://doi.org/10.1016/j.jsxm.2019.09.003)

84 Connelly PJ, Marie Freel E, Perry C, Ewan J, Touyz RM, Currie G $\&$ Delles C. Gender-affirming hormone therapy, vascular health and cardiovascular disease in transgender adults. Hypertension 201974 1266-1274. (https://doi.org/10.1161/ HYPERTENSIONAHA.119.13080)

85 Maraka S, Singh Ospina N, Rodriguez-Gutierrez R, DavidgePitts CJ, Nippoldt TB, Prokop LJ \& Murad MH. Sex steroids and cardiovascular outcomes in transgender individuals: a systematic review and meta-analysis. Journal of Clinical Endocrinology and Metabolism 2017102 3914-3923. (https://doi.org/10.1210/jc.201701643)

86 El Khoudary SR, Aggarwal B, Beckie TM, Hodis HN, Johnson AE, Langer RD, Limacher MC, Manson JE, Stefanick ML, Allison MA et al. Menopause transition and cardiovascular disease risk: implications for timing of early prevention: a scientific statement from the American Heart Association. Circulation 2020142 e506-e532. (https://doi.org/10.1161/CIR.0000000000000912)

87 Aryan L, Younessi D, Zargari M, Banerjee S, Agopian J, Rahman S, Borna R, Ruffenach G, Umar S \& Eghbali M. The role of estrogen receptors in cardiovascular disease. International Journal of Molecular Sciences 2020 21. (https://doi.org/10.3390/ijms21124314)

88 Getahun D, Nash R, Flanders WD, Baird TC, Becerra-Culqui TA, Cromwell L, Hunkeler E, Lash TL, Millman A, Quinn VP et al. Cross-sex hormones and acute cardiovascular events in transgender persons: a cohort study. Annals of Internal Medicine 2018169 205-213. (https://doi.org/10.7326/M17-2785)

89 Scheres LJJ, Selier NLD, Nota NM, van Diemen JJK, Cannegieter SC \& den Heijer M. Effect of gender-affirming hormone use on coagulation profiles in transmen and transwomen. Journal of Thrombosis and Haemostasis 202119 1029-1037. (https://doi.org/10.1111/jth.15256)

90 Shatzel JJ, Connelly KJ \& DeLoughery TG. Thrombotic issues in transgender medicine: a review. American Journal of Hematology 2017 92 204-208. (https://doi.org/10.1002/ajh.24593)

91 Scarabin PY. Progestogens and venous thromboembolism in menopausal women: an updated oral versus transdermal estrogen meta-analysis. Climacteric 201821 341-345. (https://doi.org/10.1080 /13697137.2018.1446931)

92 Kuhl H. Pharmacology of estrogens and progestogens: influence of different routes of administration. Climacteric 20058 (Supplement 1) 3-63. (https://doi.org/10.1080/13697130500148875)

93 Wiepjes CM, de Jongh RT, de Blok CJ, Vlot MC, Lips P, Twisk JW $\&$ den Heijer M. Bone safety during the first ten years of genderaffirming hormonal treatment in transwomen and transmen. 
Journal of Bone and Mineral Research 201934 447-454. (https://doi. org/10.1002/jbmr.3612)

94 Singh-Ospina N, Maraka S, Rodriguez-Gutierrez R, Davidge-Pitts C, Nippoldt TB, Prokop LJ \& Murad MH. Effect of sex steroids on the bone health of transgender individuals: a systematic review and meta-analysis. Journal of Clinical Endocrinology and Metabolism 2017 102 3904-3913. (https://doi.org/10.1210/jc.2017-01642)

95 Vlot MC, Wiepjes CM, de Jongh RT, T'Sjoen G, Heijboer AC \& den Heijer M. Gender-affirming hormone treatment decreases bone turnover in transwomen and older transmen. Journal of Bone and Mineral Research 201934 1862-1872. (https://doi.org/10.1002/ jbmr.3762)

96 Wiepjes CM, de Blok CJ, Staphorsius AS, Nota NM, Vlot MC, de Jongh RT \& den Heijer M. Fracture risk in trans women and trans men using long-term gender-affirming hormonal treatment: a nationwide cohort study. Journal of Bone and Mineral Research 2020 35 64-70. (https://doi.org/10.1002/jbmr.3862)

97 Motta G, Marinelli L, Barale M, Brustio PR, Manieri C, Ghigo E, Procopio M \& Lanfranco F. Fracture risk assessment in an Italian group of transgender women after gender-confirming surgery. Journal of Bone and Mineral Metabolism 202038 885-893. (https://doi. org/10.1007/s00774-020-01127-9)

98 Jackson SS, Han X, Mao Z, Nogueira L, Suneja G, Jemal A \& Shiels MS. Cancer stage, treatment, and survival among transgender patients in the United States. Journal of the National Cancer Institute 2021 In press. (https://doi.org/10.1093/jnci/djab028)

99 Maglione KD, Margolies L, Jaffer S, Szabo J, Schmidt H, Weltz C \& Sonnenblick EB. Breast cancer in male-to-female transsexuals: use of breast imaging for detection. American Journal of Roentgenology 2014 203 W735-W740. (https://doi.org/10.2214/AJR.14.12723)

100 de Nie I, de Blok CJM, van der Sluis TM, Barbé E, Pigot GLS, Wiepjes CM, Nota NM, van Mello NM, Valkenburg NE, Huirne J et al. Prostate cancer incidence under androgen deprivation: nationwide cohort study in trans women receiving hormone treatment. Journal of Clinical Endocrinology and Metabolism 2020105 e3293-e3299. (https://doi.org/10.1210/clinem/dgaa412)

101 Sharif A, Malhotra NR, Acosta AM, Kajdacsy-Balla AA, Bosland M, Guzman G, Prins GS \& Abern MR. The development of prostate adenocarcinoma in a transgender male to female patient: could estrogen therapy have played a role? Prostate 201777 824-828. (https://doi.org/10.1002/pros.23322)

102 Barzi A, Lenz AM, Labonte MJ \& Lenz HJ. Molecular pathways: estrogen pathway in colorectal cancer. Clinical Cancer Research 2013 19 5842-5848. (https://doi.org/10.1158/1078-0432.CCR-13-0325)

103 Xie SH \& Lagergren J. The male predominance in esophageal adenocarcinoma. Clinical Gastroenterology and Hepatology 201614 338.e1-347.e1. (https://doi.org/10.1016/j.cgh.2015.10.005)

104 Xie SH, Ness-Jensen E, Rabbani S, Langseth H, Gislefoss RE, Mattsson F \& Lagergren J. Circulating sex hormone levels and risk of esophageal adenocarcinoma in a prospective study in men. American Journal of Gastroenterology 2020115 216-223. (https://doi. org/10.14309/ajg.0000000000000446)

105 Middle JG \& Kane JW. Oestradiol assays: fitness for purpose? Annals of Clinical Biochemistry 200946 441-456. (https://doi.org/10.1258/ acb.2009.009102)

106 Fernández R, Delgado-Zayas E, Ramírez K, Cortés-Cortés J, GómezGil E, Esteva I, Almaraz MC, Guillamon A \& Pásaro E. Analysis of four polymorphisms located at the promoter of the estrogen receptor alpha ESR1 gene in a population with gender incongruence. Sexual Medicine 20208 490-500. (https://doi.org/10.1016/j. esxm.2020.04.002)

107 Darabi M, Ani M, Panjehpour M, Rabbani M, Movahedian A \& Zarean E. Effect of estrogen receptor $\beta$ A1730G polymorphism on ABCA1 gene expression response to postmenopausal hormone replacement therapy. Genetic Testing and Molecular Biomarkers 2011 15 11-15. (https://doi.org/10.1089/gtmb.2010.0106)

108 Jellinger PS, Handelsman Y, Rosenblit PD, Bloomgarden ZT, Fonseca VA, Garber AJ, Grunberger G, Guerin CK, Bell DSH, Mechanick JI et al. American Association of Clinical Endocrinologists and American College of Endocrinology guidelines for management of dyslipidemia and prevention of cardiovascular disease. Endocrine Practice 201723 (Supplement 2) 1-87. (https://doi.org/10.4158/ EP171764.APPGL)

109 Periti P, Mazzei T \& Mini E. Clinical pharmacokinetics of depot leuprorelin. Clinical Pharmacokinetics 200241 485-504. (https://doi. org/10.2165/00003088-200241070-00003)

Received 21 January 2021

Revised version received 25 May 2021

Accepted 3 June 2021 